\title{
Redesigning Cockpits
}

\author{
Lucia A. Reisch • Cass R. Sunstein
}

Received: 20 May 2014 / Accepted: 20 May 2014/

Published online: 30 May 2014

(C) Springer Science+Business Media New York 2014

In the midst of World War II, the US military saw a large number of "wheels' up" crashes, which occur when pilots retract the wheels rather than the flaps. The sheer number of crashes appeared to raise a psychological question: Why were American pilots so careless? To answer that question, the authorities enlisted a psychologist, Lieutenant Alphonse Chapanis, to figure out what was causing the problem (Mullainathan and Shafir 2013).

Chapanis quickly learned that the mistakes were being made by bomber pilots, flying a particular set of planes, and not by transport pilots. But that finding raised more questions: What was wrong with the bomber pilots? Were they under some kind of stress? Were they tired? Poorly trained? Poorly chosen? Champanis' answer came from investigating, not pilot psychology, but the bombers' cockpits. In the bombers, the wheel controls and the flap controls were right next to each other, and they looked identical. In the transport planes, the two sets of controls looked very different. Chapanis' solution? He put a rubber wheel on the landing wheel lever so that pilots would not get confused about which lever to pull (ibid.).

In thinking about social problems and human behaviour, economists typically focus on incentives. If the goal is to reduce consumption of a product, the standard economic prescription is to raise its price. But the pilots had strong incentives, and the right ones. They did not want to crash their planes (and risk their lives). The underlying problem involved is not incentives but the architecture of the cockpit. What pilots chose was a product of that architecture. When the wheel controls and the flap controls were difficult to differentiate, pilots made a large number of serious mistakes.

Behavioural scientists have spent a great deal of time studying people's mistakes. In some ways, the last 40 years of behavioural science might be described as the systematic study of human error (Thaler 1994). We know, for example, that people use certain heuristics in evaluating risks, and that these heuristics lead to blunders (Kahneman 2011); that people procrastinate and are prone to inertia; that people are especially averse to losses (ibid.); that they are vulnerable to framing effects; that people can suffer from both "present bias," focusing unduly on the short-term, and unrealistic optimism, leading them to fail to take precautions; and that people do not see certain aspects of products and activities because those aspects are

\footnotetext{
L. A. Reisch $(\bowtie)$

Department of Intercultural Communication and Management, Copenhagen Business School, Porcelaenshaven 18a, 2000 Frederiksberg, Denmark e-mail: 1r.ik@cbs.dk

C. R. Sunstein

Harvard Law School, 1563 Massachusetts Avenue, Cambridge, MA 02138, USA
} 
"shrouded," in the sense that they are neither salient nor highly visible. There is, of course, much more (ibid.). All of these findings have important implications for the environmental protection and the general idea of sustainability.

Recently, however, behavioural scientists, behavioural economists, and behaviourally informed policy analysts have placed less emphasis on human error, and much more on the relationship between human behaviour and the social background-on analogues to the cockpit (Mullainathan and Shafir 2013). When the wheel controls and the flap controls were close together and essentially identical, pilots were effectively nudged to err. Consumers operate in their own sorts of cockpits. If a grocery store puts unhealthy foods next to healthy ones and makes them look identical, many consumers will buy unhealthy foods by mistake. And if consumers cannot distinguish between energy-efficient products and energy-inefficient alternatives, they will err as well. They will err even more if energy-efficient products are hard to find, or if it is difficult for them to understand the economic and environmental benefits of energy-efficient products.

Attention to the cockpit, or to choice architecture, opens up a wide range of options for policy design. For example, default rules can have a large impact on consumer behaviour (Sunstein and Reisch 2014), and choice architects have a wide range of other tools by which to influence decisions (Johnson et al. 2012). In the environmental domain, as elsewhere, default rules tend to be particularly powerful. But it would also be possible, for example, to emphasise social norms (Allcott and Rogers 2012); to provide purely factual information (Loewenstein et al. 2014); to offer warnings; to frame options in particular ways (Willis 2013); to make sure that certain items appear first or last (Hanks et al. 2013; Dayan and Bar-Hillel 2011; Wansink 2004); to require active choosing, perhaps on a frequent basis (Rebonato 2012); to provide the equivalent of "maps"; to offer frequent reminders; and to make certain variables or product characteristics highly salient.

The repertoire of choice-preserving interventions, or "nudges," is constantly expanding. Such approaches are receiving attention not only from the private sector but also from governments all over the world, not least because they offer the hope, and sometimes even the promise, of effective reforms that do not impose significant costs on consumers or taxpayers. As the articles in this issue suggest, default rules can serve as especially important reforms. As the articles also suggest, a great deal remains to be done. We suggest that it is important to work along two quite different tracks. The first involves ethical issues; the second involves empirical questions.

In many parts of the world, the idea of paternalism is not especially appealing, though of course there are significant differences among nations on this count (a point to which we will return). It is reasonable to ask: When, exactly, is it legitimate for a government to affect consumer behaviour? One possible answer, associated with John Stuart Mill, is that if consumers are not harming others, they should be able to make their own choices, and should not even be "nudged" (Glaeser 2006). Even if we accept this answer, we might insist that there is a considerable room for behaviourally informed approaches whenever consumer choices affect other people - as they typically do when environmental issues are involved (Sunstein and Reisch 2014). Suppose, for example, that a democratic government is concerned about air pollution, including emissions of greenhouse gases. In such cases, mandates have a legitimate place, as do economic incentives, but nonprice interventions, including behaviourally informed strategies, can have a significant impact (Allcott and Mullainathan 2010). Indeed, behaviourally informed approaches might be even more effective, and even more costeffective (ibid.).

We might also wonder about the claim that behaviourally informed approaches are illegitimate even when harm to others is not involved. Suppose, for example, that fuel 
economy and energy efficiency rules could save consumers a great deal of money, and that consumers do not make ideal choices from the standpoint of their own welfare (Bubb and Pildes 2014). If we prize consumer sovereignty, we might wonder how this could be so, but consumers might be mistaken about the kinds of choices that are best for them (cf. Kahneman 2011), and in any case, their cockpits are sometimes poorly designed.

If so, mandates might themselves be justified on welfare grounds (Bubb and Pildes 2014; Conly 2012). It follows that even welfare is the master concept, some behaviourally informed approaches might legitimately take the form of mandates or bans. The argument for nudges is stronger still, because they allow consumers to go their own way (Sunstein and Reisch 2014). In some respects, they operate like a GPS, in the sense that they provide guidance that consumers can follow if they wish (Thaler and Tucker 2013). To this point, it might be added that some forms of nudging are essentially inevitable even if we have not acknowledged them. No cockpit lacks a design, and consumers are inevitably making choices against a background that nudges them in certain directions. In our view, this point can be counted as a decisive objection to those who reject nudging as such.

Having said that, we should agree that hard questions are easy to imagine, raising serious ethical issues from the standpoint of both welfare and autonomy. When should consumers be asked to make active choices? When are defaults preferable to active choosing? When is purely factual information better than a default (or some other kind of nudge)? What are the limits on the use of social norms? When does nudging become manipulation? These questions receive attention in this issue - and they will deserve far more attention in the future. One way to make progress would be to focus directly on the costs of decisions and the costs of errors. If a particular approach would minimise the sum of those two sets of costs, there is a strong argument on its behalf. Suppose, for example, that a certain default rule would reduce the costs of decisions and also lead to results that are highly desirable from the standpoint of consumers themselves. If so, there is a strong argument for that default rule. We do not contend that an inquiry into decision costs and error costs exhausts the ethical questions, but it does provide helpful orientation, and perhaps, it can help make some apparently intractable (and abstract) disputes more tractable (and less abstract).

The empirical questions are at least equally pressing. Indeed, some of the ethical questions can and should be studied in empirical terms, by asking about people's considered judgments about those questions (Felsen et al. 2013; Loewenstein et al. 2014). With respect to the effects of behaviourally informed interventions, social scientists and policymakers have learned a great deal over the last decades, especially with the benefit of randomised control trials (Banerjee and Duflo 2011). Even with these advances, we believe that our understanding remains in its adolescence, and perhaps even in childhood.

When, for example, do disclosure policies actually affect consumers? On that question, the most substantial questions are unanswered, with some evidence that at least in some contexts, consumers are often not much affected, but that producers do alter their offerings (Loewenstein et al. 2014). To what extent are consumers affected by environmental considerations, or by other factors that do not involve economic self-interest? With respect to savings behaviour, automatic enrollment has had an extremely significant impact, indeed a larger impact than substantial tax incentives (Chetty et al. 2012). Are there analogues for the environment? With respect to climate change in particular, exactly how much can be achieved through improved architecture? When are mandates or incentives necessary or preferable (Conly 2012)? How can developing nations use behavioural findings to obtain the right balance between economic and environmental variables? And what kinds of cultural differences can we find on the empirical questions? Do different nations, and different ethnic groups, react differently to behaviourally informed interventions? How can we explain and respond to heterogeneity? 
The articles in this issue cast light on many of these questions. Our hope is that they might contribute to an improved design of the countless cockpits of modern societies. The seven papers offer both positive and more critical accounts of behaviourally informed regulation and its tools, as well as hands-on applications of behavioural findings to environmentally relevant consumer behaviour. Reflecting the different disciplines that are crucial to thoroughly developing and promoting research in the field of behavioural economics, policy, and law, our authors come from diverse disciplines such as environmental psychology, economic psychology, experimental economics, resource economics, decision sciences, and public policy as well as applied mathematics and consumer law.

In Informing versus Nudging in Environmental Policy, Folke Ölander, the late founding editor of this journal, and his successor John Thøgersen from Denmark's Aarhus University compare "nudging" as a tool in environmental policy with the classical approach of providing consumers with information (information provision can, of course, be understood as a nudge). While acknowledging that information has not been proven to be a very successful means of promoting voluntary behaviour change to protect the environment, and while finding significant effects from nudges, they are also critical of recommendations from behavioural economics, which focus on making the choice architecture more facilitating for the desired behaviour. The authors present three studies demonstrating how mental shortcuts, based on subtle cues in the context, unconsciously influence human decision-making, with important consequences for the environment. Two of their own studies illustrate the behavioural impacts of anchoring (the design of the European energy label) and default effects (the framing of a request to participate in the Smart Grid). Moreover, they use the data from a study by Göckeritz et al. (2010) to illustrate the impacts of herding or descriptive norms (the social context of energy saving). While acknowledging these effects, Ölander and Thøgersen point to what they see as theoretical weaknesses in behavioural economics and call for research into strengthening the theoretical underpinnings of this approach to behaviour change.

Riccardo Rebonato, a lecturer at the Mathematics Institute at the University of Oxford, sets out a more general Critical Assessment of Libertarian Paternalism. In particular, he assesses to what extent libertarian paternalism lives up to its libertarian credentials, and whether this "softer" version of paternalism is more or less desirable than the traditional, more coercivebut as he claims, also more transparent - form. Rebonato's key argument is that the distinction between effective and nominal ability to reverse a nudge is more important than its theoretical ease of reversibility - the more so, if anchoring, framing, and status quo bias are as powerful as the libertarian paternalists maintain. If the libertarian paternalistic nudges are effective, but not always transparent, Rebonato argues that this effectiveness raises some (not yet adequately addressed) questions, namely, about the legitimacy of the interventions; about how the true preferences of the consumer can be ascertained by the choice architect and the role played by rationality in this process; and about the effective respect of her autonomy. Finally, he highlights some alternatives to "nudging" which place greater emphasis on the full process of choice, rather than on its outcomes. These approaches, he claims, could better preserve true autonomy of choice.

The following four articles use theory and empirical insights from psychology and behavioural economics, and investigate whether applying them can initiate consumer behaviour change towards more environmentally friendly solutions. In their article, Aiding Decision Making to Reduce the Impacts of Climate Change, Wharton School's Howard Kunreuther and Columbia University-based Elke U. Weber examine individuals' cognitive and motivational barriers to adopting climate change adaptation and mitigation measures that increase consumer welfare. They explore various strategies that take into account the simplified decision-making processes used by individuals and resulting biases. The authors make these points by working 
through two examples: firstly, investments in energy efficiency products and new technology and secondly, adaptation measures to reduce property damage from future floods and hurricanes. In both cases, there is a reluctance to undertake these measures due to high and certain upfront costs, delayed and probabilistic benefits, and behavioural biases related to this asymmetry. Their research shows that the use of choice architecture through framing and the use of default options coupled with short-term incentives and long-term contracts can encourage greater investment in these measures.

Energy conservation results in environmental (reduced emissions) and financial (reduced costs) savings. Consumers' perception of the worthiness of changes in behaviour may differ depending on whether environmental or financial savings are emphasised. In Making Small Numbers Count: Environmental and Financial Feedback in Promoting Eco-driving Behaviours, a French-Dutch research team, Ebru Dogan, Jan Willem Bolderdijk, and Linda Steg, investigates the effects of using either environmental or financial feedback in the context of eco-driving. In their study, participants evaluated six scenarios describing different eco-driving behaviours. Participants in experimental groups were informed about either the environmental or financial savings realised by adopting the behaviours. A control group did not receive information on possible savings. Results indicated that, unlike commonly assumed, environmental savings are considered more worthwhile than commensurate financial savings (at least within this population). Yet, intentions to adopt eco-driving behaviours were mainly sensitive to the presence of feedback per se, rather than the content of feedback. The theoretical and practical implications of these findings should be further discussed.

Avoiding waste of all kinds has become a key strategy of environmentally sound consumption. One widely spread kind of waste is junk mail that burdens consumers everywhere. Attaching "No junk mail!" stickers to mailboxes - in most countries legally enforceableoffers a simple solution for protecting against unwanted paper ads. Georg Liebig and Jens Rommel from Humboldt University in Berlin presume that the use of such stickers can be increased if consumers deliberately decide either for or against receiving junk mail. In Active and Forced Choice for Overcoming Status Quo Bias: A Field Experiment on the Adoption of "No junk mail" Stickers in Berlin, Germany, they put this conjecture of status quo bias on the test bed and report on a field experiment run with more than 900 households. In one treatment, stickers were put into mailboxes, facilitating active choice; in a second treatment, stickers were attached halfway onto the outsides of mailboxes, forcing consumers to either remove or fully attach them. They found that roughly fifth of the sample attached a sticker after treatment. With an uptake of more than 21 , as compared to $16 \%$, the forced choice was more effective than the active choice treatment. The authors conclude that their findings highlight the importance of green nudges and defaults for promoting pro-environmental behaviour, suggesting policy implications for the handling of such matters by landlords and housing companies.

A research team from Georgia State University led by Paul J. Ferraro and Michael Price sets out to investigate the difficult — and often untouched - question of longer-term impacts of behavioural nudges to achieve public policy objectives. In The Persistent Impacts of NormBased Messaging and Their Implications for Water Conservation, they report on a randomised experimental design with over 100,000 households in which they study the longer-term impacts of a one-time behavioural nudge that aims to induce voluntary reductions in water use during a drought. Combining technical information, moral suasion, and social comparisons, the nudge has a surprisingly persistent effect. Although its effect size declines by almost $50 \%$ after 1 year, it remains detectable and policy-relevant even 6 years later. Further analysis suggests that the intervention works through both short-lived behavioural adjustments and longer-lived adjustments to habits or physical capital. Treatment effects are not detectable in homes from which the treated consumers have moved, which provides suggestive evidence 
that these longer-lived adjustments are mobile rather than incorporated into the housing stock. Also, the persistence of the effect makes the intervention more cost-effective than previously assumed (cost drops by almost 60\%). Nevertheless, water utilities may find this persistence undesirable if the nudges are intended to have only a short-run effect on demand during environmental emergencies.

The final contribution of this special issue comes from an author with a background in law. Kai Purnhagen from the Dutch University of Wageningen focuses on the precautionary principle, a key approach of European regulation. In The Behavioural Law and Economics of the Precautionary Principle in the EU and Its Impact on Internal Market Regulation, Purnhagen argues that the precautionary principle contributes to "the social aspect" of internal market regulation as it counterbalances the loss aversion and availability bias of regulators who may too hastily endorse measures based on furthering fundamental freedoms instead of fundamental rights and environmental protection. According to the author, the precautionary principle also enhances the regulatory power of the European Union: By way of regulating via the precautionary principle, European institutions pretend to have answers to citizens' fears. These fears result from a crisis of causality, as society is trying to find a meaning to what sometimes appears as a series of patternless events. In essence, Purnhagen claims that the European legal order not only takes advantage of these effects and creates an image of being able to cope with these fears but also that it may be questioned whether the legal order is living up to these expectations.

We are hopeful that the various essays might contribute to both theory and practice in these important domains. We are most grateful to our supportive reviewers, who have contributed in reviewing about two dozen submissions for this special issue.

\section{References}

Allcott, H., \& Mullainathan, S. (2010). Behavior and energy policy. Science, 327(5970), 1204-1205.

Allcott, H., \& Rogers, T. (2012). The short-run and long-run effects of behavioral interventions: Experimental evidence from energy conservation. National Bureau of Economic Research Working Paper 18492.

Banerjee, A., \& Duflo, E. (2011). Poor economics: A radical rethinking of the way to fight global poverty. New York: Public Affairs.

Bubb, R., \& Pildes, R. (2014). How behavioral economics trims its sails and why. Harvard Law Review, 127, 1593-1678.

Chetty, R., Friedman, J., Leth-Petersen, S., Nielsen, T., \& Olsen, T. (2012). Active vs. passive decisions and crowd out in retirement savings accounts: Evidence from Denmark. NBER Working Paper No. 18565. Available at http://www.nber.org/papers/w18565.

Conly, S. (2012). Against autonomy: Justifying coercive paternalism. Cambridge: Cambridge University Press.

Dayan, E., \& Bar-Hillel, M. (2011). Nudge to nobesity II: Menu positions influence food orders. Judgment and Decision Making, 6(4), 333-342.

Felsen, G., Castelo, N., \& Reiner, P. B. (2013). Decisional enhancement and autonomy: Public attitudes towards overt and covert nudges. Judgment and Decision Making, 8(3), 202-213.

Glaeser, E. L. (2006). Paternalism and psychology. University of Chicago Law Review, 73, 133-156.

Göckeritz, S., Rendón, T., Schultz, P. W., Cialdini, R., Goldstein, N., \& Griskevicius, V. (2010). Normative social influence: The moderating roles of personal involvement and injunctive normative beliefs. European Journal of Social Psychology, 40, 514-523.

Hanks, A., Just, D., \& Wansink, B. (2013). Smarter lunchrooms can address new school lunchroom guidelines and childhood obesity. Journal of Pediatrics, 162, 867-869.

Johnson, E., Shu, S., Dellaert, B., Fox, C., Goldstein, D., Haubl, G., Larrick, R., et al. (2012). Beyond nudges: Tools of a choice architecture. Marketing Letters, 23(2), 487-504.

Kahneman, D. (2011). Thinking, fast and slow. New York: Farrar, Straus and Giroux.

Loewenstein, G., Sunstein, C. R., \& Golman, R. (2014). Disclosure: Psychology changes everything. Annual Review of Economics. doi:10.1146/annurev-economics-080213-041341.

Mullainathan, S., \& Shafir, E. (2013). Scarcity: Why having too little means so much. New York: Times Books. 
Rebonato, R. (2012). Taking liberties: A critical examination of libertarian paternalism. Palgrave McMillan: Basingstoke.

Sunstein, C. R., \& Reisch, L. A. (2014). Automatically green. Behavioral economics and environmental protection. Harvard Environmental Law Review, 38, 128-158.

Thaler, R. H. (1994). Quasi rational economics. New York: Russell Sage.

Thaler, R. H., \& Tucker, W. (2013). Smarter information, smarter consumers. Harvard Business Review, 45-54.

Wansink, B. (2004). Environmental factors that increase the food intake and consumption volume of unknowing consumers. Annual Review of Nutrition, 24, 455-479.

Willis, L. (2013). When nudges fail: Slippery defaults. University of Chicago Law Review, 80, 1155-1229. 